\title{
Vagal blockade suppresses the phase I heart rate response but not the phase I cardiac output response at exercise onset in humans
}

\author{
Timothée Fontolliet $^{1,2}\left({ }^{10} \cdot\right.$ Aurélien Bringard $^{3} \cdot$ Alessandra Adami $^{4} \oplus \cdot$ Nazzareno Fagoni $^{2,5} \cdot$ Enrico Tam $^{6}$. \\ Anna Taboni ${ }^{1,2} \cdot$ Guido Ferretti ${ }^{1,2,7}$
}

Received: 19 March 2021 / Accepted: 9 July 2021 / Published online: 14 August 2021

(C) The Author(s) 2021

\begin{abstract}
Purpose We tested the vagal withdrawal concept for heart rate (HR) and cardiac output $(\mathrm{CO})$ kinetics upon moderate exercise onset, by analysing the effects of vagal blockade on cardiovascular kinetics in humans. We hypothesized that, under atropine, the $\varphi_{1}$ amplitude $\left(A_{1}\right)$ for HR would reduce to nil, whereas the $A_{1}$ for $\mathrm{CO}$ would still be positive, due to the sudden increase in stroke volume (SV) at exercise onset.

Methods On nine young non-smoking men, during 0-80 W exercise transients of 5-min duration on the cycle ergometer, preceded by 5-min rest, we continuously recorded $\mathrm{HR}, \mathrm{CO}, \mathrm{SV}$ and oxygen uptake $\left(\dot{V} \mathrm{O}_{2}\right)$ upright and supine, in control condition and after full vagal blockade with atropine. Kinetics were analysed with the double exponential model, wherein we computed the amplitudes $(A)$ and time constants $(\tau)$ of phase $1\left(\varphi_{1}\right)$ and phase $2\left(\varphi_{2}\right)$.

Results In atropine versus control, $A_{1}$ for HR was strongly reduced and fell to $0 \mathrm{bpm}$ in seven out of nine subjects for HR was practically suppressed by atropine in them. The $A_{1}$ for CO was lower in atropine, but not reduced to nil. Thus, SV only determined $A_{1}$ for CO in atropine. $A_{2}$ did not differ between control and atropine. No effect on $\tau_{1}$ and $\tau_{2}$ was found. These patterns were independent of posture.

Conclusion The results are fully compatible with the tested hypothesis. They provide the first direct demonstration that vagal blockade, while suppressing $\operatorname{HR} \varphi_{1}$, did not affect $\varphi_{1}$ of CO.
\end{abstract}

Keywords Heart rate $\cdot$ Stroke volume $\cdot$ Cardiac output $\cdot$ Exercise transients $\cdot$ atropine

\section{Abbreviations}

$A_{1} \quad$ Amplitude of the first phase in double exponential model

$A_{2} \quad$ Amplitude of the second phase in double exponential model

Communicated by Susan Hopkins .

Timothée Fontolliet and Aurélien Bringard contributed equally.

Timothée Fontolliet

timothee.fontolliet@unige.ch

1 Department of Basic Neurosciences, University of Geneva, Geneva, Switzerland

2 Department of Anaesthesiology, Clinical Pharmacology, Intensive Care and Emergency Medicine, University of Geneva, Geneva, Switzerland

3 Pulmunology Service, Geneva University Hospitals, Geneva, Switzerland

$\begin{array}{ll}\text { ANOVA } & \text { Analysis of variance } \\ \mathrm{CaO}_{2}-\mathrm{C} \bar{\nu} \mathrm{O}_{2} & \text { Arterial-venous } \mathrm{O}_{2} \text { difference } \\ \mathrm{CO} & \text { Cardiac output } \\ \mathrm{CO}_{2} & \text { Carbon dioxide } \\ \mathrm{HR} & \text { Heart rate } \\ {[\mathrm{La}] \mathrm{b}} & \text { Blood lactate concentration } \\ \mathrm{MAP} & \text { Mean arterial pressure } \\ \mathrm{PCO}_{2} & \text { Partial pressure of } \mathrm{CO}_{2}\end{array}$

4 Department of Kinesiology, University of Rhode Island, Kingston, RI, USA

5 AAT Brescia, Azienda Regionale Emergenza Urgenza (AREU), ASST Spedali Civili di Brescia, Brescia, Italy

6 Department of Neurosciences, Biomedicine and Movement Sciences, University of Verona, Verona, Italy

7 Department of Molecular and Translational Medicine, University of Brescia, Brescia, Italy 


$\begin{array}{ll}\mathrm{pH} & \begin{array}{l}\text { Negative logarithm of hydrogen ion } \\ \text { concentration }\end{array} \\ \mathrm{SV} & \begin{array}{l}\text { Stroke volume } \\ \text { Carbon dioxide output }\end{array} \\ \dot{\mathrm{V}} \mathrm{CO}_{2} & \text { Oxygen uptake } \\ \dot{V} \mathrm{O}_{2} & \text { First phase of the double exponential model } \\ \varphi_{1} & \text { Second phase of the double exponential } \\ \varphi_{2} & \text { model } \\ & \text { Time constant }\end{array}$

\section{Introduction}

The oxygen uptake $\left(\dot{V} \mathrm{O}_{2}\right)$ kinetics at the onset of a moderate-intensity exercise is characterised by two distinct phases (Whipp et al. 1982), which have been modelled as a sum of two exponentials (Barstow and Molé 1987). The first rapid phase $\left(\varphi_{1}\right)$ has been ascribed to a sudden increase in cardiac output (CO) and was called "cardiodynamic phase" (Wasserman et al. 1974). The demonstration of a rapid increase in $\mathrm{CO}$ at exercise onset is the strongest piece of evidence supporting this interpretation (Cummin et al. 1986; Eriksen et al. 1990; De Cort et al. 1991; Yoshida et al. 1993). The second or primary phase $\left(\varphi_{2}\right)$, slower than $\varphi_{1}$, was attributed to muscle metabolic adaptations (di Prampero 1981; Whipp and Ward 1990; Poole and Jones 2012; Ferretti 2015). Application of the double exponential model to the analysis of the CO kinetics at exercise onset led to the demonstration that the $\varphi_{1}$ for $\dot{V} \mathrm{O}_{2}$ kinetics may be entirely explained by the $\varphi_{1}$ for CO (Faisal et al. 2009; Lador et al. 2006, 2008).

Two different mechanisms have been hypothesised to explain the $\varphi_{1}$ for CO. On one side, some authors postulated that a sudden fall in vagal activity occurs at exercise start, leading to a fast increase in heart rate (HR) and, thus, in CO (Fagraeus and Linnarsson 1976; Fontolliet et al. 2018; Lador et al. 2006, 2008): this is the so-called vagal withdrawal concept, although even an incomplete withdrawal of vagal modulation of HR was recently considered sufficient to explain the phenomenon (White and Raven 2014). On the other side, some authors postulated that at exercise start there is a rapid increase in venous return, due to sudden displacement of blood from the contracting muscles to the heart by muscle pump action. This would lead to an immediate increase in stroke volume (SV) and, thus, in CO (Laughlin 1987; Leyk et al. 1994; Linnarsson et al. 1996; Wieling et al. 1996; Sundblad et al. 2000; Schneider et al. 2002; Stenger et al. 2012). Fagoni et al. (2020) argued that these two postulated mechanisms may coexist and are not mutually exclusive, one driven by HR, and the other by SV.

In the present study, the vagal withdrawal concept for CO kinetics, which thus far has only received indirect support, was tested. Fagraeus and Linnarsson (1976) demonstrated the disappearance of $\varphi_{1}$ for HR after complete vagal withdrawal with atropine without measuring $\mathrm{CO}$. Lador et al. (2008) demonstrated that in acute hypoxia (i.e. a condition characterised by lower vagal activity than normoxia) the amplitude of $\varphi_{1}\left(A_{1}\right)$ for HR and CO kinetics was lower than in normoxia. Moreover, a rapid initial component in HR on-kinetics was not found in heart transplant recipients (Grassi et al. 1997).

All this evidence was indirect. The vagal withdrawal concept for $\mathrm{CO}$ was not tested under vagal blockade so far. Vagal blockade inhibits the parasympathetic modulation of heart activity already at rest. Therefore, no vagal withdrawal should occur at exercise onset under vagal blockade. If the hypothesis by Fagoni et al. (2020) is correct, we should expect that, under vagal blockade, the $A_{1}$ for HR would reduce to nil, whereas the $A_{1}$ for $\mathrm{CO}$, though having a smaller size than in control condition, would still be visible and positive, due to the sudden increase in SV.

To test the vagal withdrawal concept, we aimed to determine the $\dot{V} \mathrm{O}_{2}, \mathrm{CO}$, and HR kinetics during vagal blockade with atropine, and to compare these responses with control conditions. We analysed the data using the double exponential model and we computed the characteristic parameters of $\varphi_{1}$ (amplitude and time constant) for the three measured variables.

\section{Methods}

\section{Subjects}

Nine healthy non-smoking men subjects took part in the study. They were (mean \pm SD) $23 \pm 3$ years old, $180 \pm 3 \mathrm{~cm}$ tall, and $77 \pm 6 \mathrm{~kg}$ heavy.

\section{Protocol}

Subjects were asked to come to the laboratory on two separate days, one for the protocol under vagal blockade and one for the control condition. During each testing session, the protocol was carried out in both upright and supine position, administered in a random order. Parasympathetic blockade was obtained by injecting a single dose of $0.04 \mathrm{mg} / \mathrm{kg}$ (mean $3.06 \pm 0.23 \mathrm{mg}$, range $2.7-3.4 \mathrm{mg}$ ) of atropine, using a short indwelling venous catheter in an antecubital vein (Yasue et al. 1986; Morikami et al. 1988; Goldberger et al. 2001; Ferretti et al. 2005; Fontolliet et al. 2018).

After participants' preparation and instrument calibration, 3-min rest monitoring recordings were performed, during which blood sampling and $\mathrm{CO}$ determination with the acetylene method were done. Then, the subject was asked to perform three exercise transients from 0 to $80 \mathrm{~W}$. The starting signal was provided by a verbal countdown. The flywheel was not pre-accelerated. The first bout lasted 6 to $7 \mathrm{~min}$, to 
allow blood sampling and $\mathrm{CO}$ determination with the acetylene method after 5 min of exercise (at exercise steady state), while the second and third bouts lasted $5 \mathrm{~min}$, at the end of which only blood sampling was taken. Each exercise bout was followed by 6 min of recovery, during which [La $]_{b}$ blood sampling was performed at minutes 1,3 , and 5 .

\section{Measurements}

The time course of oxygen and carbon dioxide partial pressures throughout the respiratory cycles were continuously monitored by a mass spectrometer (Balzers Prisma, Balzers, Liechtenstein) calibrated against gas mixtures of known composition. The inspiratory and expiratory ventilation was measured by an ultrasonic flowmeter (Spiroson ${ }^{\circledR}$, ECO MEDICS AG, Duernten, Switzerland) calibrated with a 31 syringe. HR was continuously measured by electrocardiography (Elmed ETM 2000, Heiligenhaus, Germany). Continuous recordings of arterial pulse pressure were obtained at a fingertip of the left arm by means of a non-invasive cuff pressure recorder (Portapres ${ }^{\circledR}$, Finapres ${ }^{\circledR}$ Medical Systems, Enschede, The Netherlands). Steady-state $\mathrm{CO}$ values were obtained by means of the open circuit acetylene method (Barker et al. 1999), with a procedure previously described (Lador et al. 2006), implying determination of partition coefficients for acetylene (Meyer and Scheid 1980). The rationale of this methodological approach was previously discussed (Lador et al. 2006, 2008).

All signals were digitalized in parallel by a 16-channel A/D converter (MP150 system with AcqKnowledge acquisition and analysis software, BIOPAC ${ }^{\circledR}$ Systems Inc., Goleta, CA, USA) and stored on a computer. The acquisition rate was $400 \mathrm{~Hz}$.

Blood lactate concentration ([La $\left.]_{b}\right)$ was measured by an electro enzymatic method (Eppendorf EBIO 6666, Erlangen, Germany) on $10 \mu \mathrm{L}$ blood samples taken from the right earlobe. Capillary blood gas composition and $\mathrm{pH}$ were measured by microelectrodes (Instrumentation Laboratory Synthesis 10, Lexington, MA, USA) on $50 \mu \mathrm{L}$ blood samples taken from the right earlobe.

\section{Ergometers}

In an upright position, subjects exercised on a standard electrically braked cycle ergometer (Ergo-metrics 800S, Ergo-line, Bitz, Germany). In the supine position, an electrically braked arm-cycle ergometer (Ergoselect 400, Ergoline $\mathrm{GmbH}$, Bitz, Germany), modified for leg pedalling in supine posture, was used. Subjects wore race cycling shoes, allowing fixation of their feet to the pedals. The subjects were asked to keep a pedalling frequency between 60 and $80 \mathrm{rpm}$ (visual feedback). The pedalling frequency was recorded, and its sudden increase at the exercise onset and decrease at the exercise offset were used as markers to precisely identify the start and the end of exercise. In both positions, the electro-mechanical characteristics of the ergometers were such as to permit workload application in less than $50 \mathrm{~ms}$.

\section{Data treatment}

Oxygen and carbon dioxide partial pressures traces were aligned with the flowmeter traces and breath-by-breath $\dot{V}$ $\mathrm{O}_{2}$ and carbon dioxide output $\left(\dot{V} \mathrm{CO}_{2}\right)$ were then computed off-line by means of a modified version of Grønlund's algorithm (1984) run in LabVIEW ${ }^{\circledR}$ environment (LabVIEW ${ }^{\circledR}$ 5.0, National Instruments ${ }^{\mathrm{TM}}$, Austin, TX, USA). The characteristics and the physiological implications of Grønlund's algorithm have been previously discussed elsewhere (Capelli et al. 2001, 2011; Lador et al. 2006).

Arterial blood pressure profiles were analysed to obtain beat-by-beat values using the Beatscope ${ }^{\circledR}$ software (Finapres ${ }^{\circledR}$ Medical Systems, Enschede, The Netherlands). The same software also provided SV by means of the Modelflow method (Wesseling et al. 1993). Beat-by-beat CO was computed as the product of single-beat SV times the corresponding single-beat HR. The data were then corrected for method's inaccuracy, as previously described (Kenfack et al. 2004; Tam et al. 2004; Lador et al. 2006). Individual correction factors were calculated at steady state, using the opencircuit acetylene $\mathrm{CO}$ values as reference, and applied during dynamic states with rapid changes in $\mathrm{CO}$ (van Lieshout et al. 2003). The calibration factors were the same at rest $(1.02 \pm 0.29)$ and exercise $(1.03 \pm 0.24$, non-significant $)$.

The three transitions of either $\dot{V} \mathrm{O}_{2}, \mathrm{CO}$ or HR were time aligned, by setting the time of exercise start as time zero for the analysis of the on-kinetics. Then $\mathrm{CO}, \mathrm{HR}$ and $\dot{V} \mathrm{O}_{2}$ traces from the three repetitions were pooled together for each subject without interpolation (Bringard et al. 2014). For each variable, the time course upon exercise onset was analysed by the double exponential model (Barstow and Mole 1987; Lador et al. 2006):

$f(t)=b+A_{1} \theta\left(t-d_{1}\right)\left(1-e^{-\frac{t-d_{1}}{\tau_{1}}}\right)+A_{2} \theta\left(t-d_{2}\right)\left(1-e^{-\frac{t-d_{2}}{\tau_{2}}}\right)$,

where $b, A, d$, and $\tau$ are the baseline values at rest, the amplitude, the time delay, and the time constant, respectively. The subscripts 1 and 2 refer to the $\varphi_{1}$ and the $\varphi_{2}$ of the on-kinetics, respectively. $\Theta$ is the Heaviside function $(\Theta(t)=0$ if $t<0$ and $\Theta(t)=1$ if $t \geq 0)$. When $A_{1}=0$, the second term of the right-hand branch of Eq. (1) cancels out. In this case, (i) $\tau_{1}$ becomes meaningless and cannot be computed so that for $\tau_{1}$ " $n$ " may be less than the number of subjects, and (ii) Eq. (1) reduces to a single exponential equation, with one time constant, equal to $\tau_{2}$, and overall amplitude of response equal to $A_{2}$. If the biexponential model provided $A_{1}$ not significantly 
different from zero, $A_{1}$ was set as equal to $0 \mathrm{~L} \mathrm{~min}^{-1}, \tau_{1}$ was neglected as meaningless, and a mono-exponential analysis of $\varphi_{2}$ was applied.

The total sum of the squared 2 residuals (RESNORM variable) was also systematically calculated by MATLAB function. The comparison of the RESNORM between double exponential and mono-exponential analysis was used as a quality check of the model. In fact, whenever we neglected $\tau_{1}$ and fitted only $\varphi_{2}$, the RESNORM analysis demonstrated that a double exponential fit did not improve the quality of fitting (RESNORM of mono-exponential fitting less than $1 \%$ lower than with double exponential fitting whenever $A_{1}=0$ $\mathrm{L} \min ^{-1}$ ).

Steady state means were calculated as the average values of the last min of rest and of the 5th min of exercise. Arterial-venous $\mathrm{O}_{2}$ concentration difference $\left(\mathrm{CaO}_{2}-\mathrm{C} \bar{v}\right.$ $\mathrm{O}_{2}$ ) was calculated at rest and at exercise steady state as the ratio between $\dot{V} \mathrm{O}_{2}$ and $\mathrm{CO}$ (Adami et al. 2014; Ferretti et al. 2017).

\section{Statistics}

Data are given as mean and standard deviation (SD) of the values obtained for each parameter from the average superimposed files of each subject, to account for inter-individual variability. Difference between rest and exercise steady state was computed as the latter minus the former $(\Delta)$. The atropine-induced effects on the primary outcomes were analysed by a 2-way ANOVA (drug and X body position). When applicable, a Tukey post hoc test was used to locate significant differences. The results were considered significant if $p<0.05$. The parameters of the models were estimated with a weighted non-linear least squares procedure (Bringard et al. 2014; Carson et al. 1983), implemented in MATLAB (version 7.9.0, MathWorks ${ }^{\circledR}$, Natick, MA, USA).

\section{Results}

\section{Resting and exercise steady-state phase}

The mean values of measured and calculated variables at rest and during exercise steady state for all conditions are reported in Table 1. HR in atropine, whether supine or upright, was higher than the control condition, both at rest $(p<0.05)$ and at exercise $(p<0.05)$. At rest in the supine position and during exercise in both postures, SV was lower under atropine than in control $(p<0.05)$. In upright posture, SV was always lower than in supine posture $(p<0.001)$, except in control during exercise $(p=0.41)$. Resting $\mathrm{CO}$ was higher in atropine than in control, whether supine or upright $(p<0.05)$. In atropine, $\mathrm{CO}$ was lower in the upright than in supine posture, both at rest and during exercise $(p<0.05)$. Oxygen uptake value did not change at rest $(p>0.18)$. During exercise under vagal blockade, $\dot{V}$ $\mathrm{O}_{2}$ was lower in upright than in supine posture $(p=0.01)$. A similar non-significant trend occurred also in control $(p>0.99)$.

The values for $[\mathrm{La}]_{\mathrm{b}}, \mathrm{pH}$, and partial pressure of $\mathrm{CO}_{2}$ $\left(\mathrm{PCO}_{2}\right)$ in capillary blood are reported in Table 2. We observed no differences between rest and exercise (respectively, $p=0.67,0.21$ and 0.07 ) or between atropine and control (respectively, $p=0.12,0.94$ and 0.08 ) in any of the investigated conditions.

Figure 1 reports the difference $(\Delta)$ between the exercise steady state and the resting value for the investigated parameters. This difference is indicative of the overall amplitude of response during the rest-exercise transition for each parameter. The $\Delta \mathrm{HR}$ was smaller under atropine than in control, when exercise was performed in both supine and upright position $(p<0.05)$. This was not the
Table $1{ }_{2}$ Mean values of measured and calculated variables at rest and during exercise steady state, in control condition and with atropineMean values of measured and calculated variables at rest and during exercise steady state, in control condition and with atropine

\begin{tabular}{|c|c|c|c|c|c|c|}
\hline & & & \multicolumn{2}{|l|}{ Control } & \multicolumn{2}{|l|}{ Atropine } \\
\hline & & & Supine & Upright & Supine & Upright \\
\hline \multirow[t]{2}{*}{ HR } & Rest & $\min ^{-1}$ & $61 \pm 10$ & $71 \pm 8$ & $105 \pm 9^{\#}$ & $109 \pm 9^{\#}$ \\
\hline & Exercise & $\min ^{-1}$ & $110 \pm 10$ & $105 \pm 10$ & $139 \pm 13^{\#}$ & $129 \pm 13^{\#}$ \\
\hline \multirow[t]{2}{*}{ SV } & Rest & $\mathrm{mL}$ & $97 \pm 13$ & $79 \pm 13^{*}$ & $78 \pm 10^{\#}$ & $66 \pm 9^{*}$ \\
\hline & Exercise & $\mathrm{mL}$ & $120 \pm 15$ & $108 \pm 9$ & $103 \pm 16^{\#}$ & $83 \pm 11^{\#, *}$ \\
\hline \multirow[t]{2}{*}{$\mathrm{CO}$} & Rest & $\mathrm{L} \min ^{-1}$ & $5.9 \pm 0.9$ & $5.6 \pm 1.0$ & $8.2 \pm 0.6^{\#}$ & $7.1 \pm 0.6^{\#, *}$ \\
\hline & Exercise & $\mathrm{L} \min ^{-1}$ & $12.9 \pm 1.8$ & $11.2 \pm 1.3$ & $14.1 \pm 2.3$ & $10.6 \pm 1.6^{*}$ \\
\hline \multirow[t]{2}{*}{$\dot{\mathrm{V}} \mathrm{O}_{2}$} & Rest & $\mathrm{L} \min ^{-1}$ & $0.44 \pm 0.06$ & $0.51 \pm 0.09$ & $0.49 \pm 0.08$ & $0.49 \pm 0.08$ \\
\hline & Exercise & $\mathrm{L} \min ^{-1}$ & $1.59 \pm 0.10$ & $1.53 \pm 0.25$ & $1.67 \pm 0.09$ & $1.43 \pm 0.13 *$ \\
\hline
\end{tabular}

Mean values of measured and calculated variables at rest and during exercise steady state, in control condition and with atropine

$H R$ heart rate, $S V$ stroke volume, $C O$ cardiac output, $\dot{V} O_{2}$ oxygen consumption, $\mathrm{min}^{-1}$ beat per minute

${ }^{*} p<0.05$ vs. supine position, within the same condition

${ }^{\#} p<0.05$ vs. control, within the same posture 
Table 2 Mean values of [La]b pH and PCO2 at rest and during exercise steady state, in control condition and with atropine

\begin{tabular}{|c|c|c|c|c|c|c|}
\hline & & & \multicolumn{2}{|l|}{ Control } & \multicolumn{2}{|l|}{ Atropine } \\
\hline & & & Supine & Upright & Supine & Upright \\
\hline \multirow[t]{2}{*}[\mathrm{La}]{$_{\mathrm{b}}$} & Rest & $\mathrm{L} \min ^{-1}$ & $0.96 \pm 0.12$ & $0.63 \pm 0.05$ & $1.13 \pm 0.12$ & $0.71 \pm 0.05$ \\
\hline & Exercise & $\mathrm{L} \min ^{-1}$ & $1.00 \pm 0.09$ & $0.68 \pm 0.10$ & $1.20 \pm 0.01$ & $0.68 \pm 0.06$ \\
\hline \multirow[t]{2}{*}{$\mathrm{pH}$} & Rest & & $7.44 \pm 0.00$ & $7.44 \pm 0.00$ & $7.44 \pm 0.00$ & $7.44 \pm 0.00$ \\
\hline & Exercise & & $7.43 \pm 0.00$ & $7.43 \pm 0.00$ & $7.43 \pm 0.01$ & $7.43 \pm 0.00$ \\
\hline \multirow[t]{2}{*}{$\mathrm{PCO}_{2}$} & Rest & $\mathrm{mmHg}$ & $37.0 \pm 0.6$ & $36.1 \pm 0.3$ & $37.3 \pm 0.5$ & $38.0 \pm 0.6$ \\
\hline & Exercise & $\mathrm{mmHg}$ & $38.7 \pm 0.9$ & $36.5 \pm 0.4$ & $38.9 \pm 0.6$ & $38.7 \pm 0.3$ \\
\hline
\end{tabular}

Mean values of $[\mathrm{La}] \mathrm{b} \mathrm{pH}$ and $\mathrm{PCO}_{2}$ at rest and during exercise steady state, in control condition and with atropine

[La] $]_{b}$ blood lactate concentration, $\mathrm{pH}$ hydrogen potential, $\mathrm{PCO}_{2}$ partial pressure of $\mathrm{CO}_{2}$

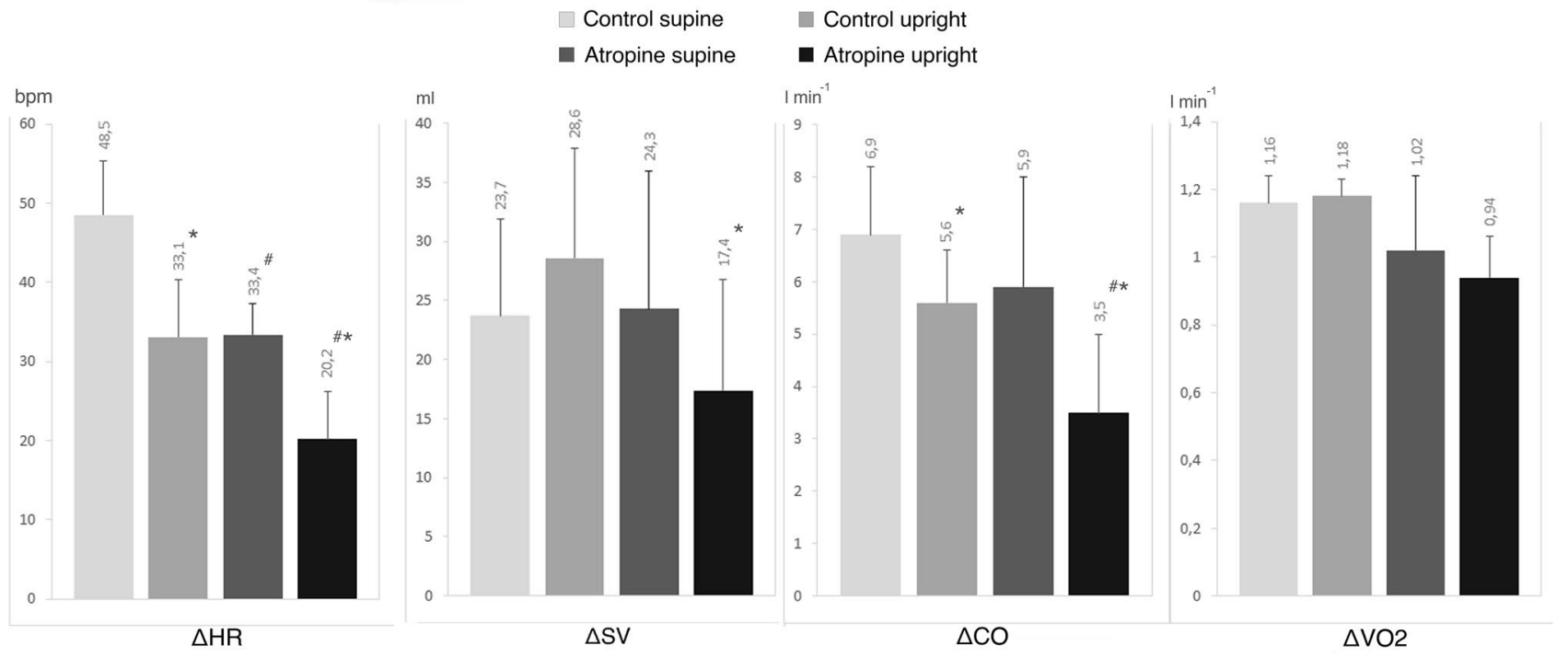

Fig. 1 Difference $(\Delta)$ in heart rate, cardiac output, stroke volume and oxygen consumption between rest and exercise steady state in supine and upright position and for control situation and with atropine

$(n=9) . \dot{V} O_{2}$ oxygen consumption, $\mathrm{CO}$ cardiac output, $H R$ heart rate, $S V$ stroke volume, ${ }^{*} p<0.05$ vs. supine position; ${ }^{\#} p<0.05$ vs. control

case for SV $(p=0.85$ and 0.06$)$ and $\dot{V} \mathrm{O}_{2}(p=0.98$ and $0.58)$ therefore, $\triangle \mathrm{CO}$ only tended to decrease in atropine with respect to control ( $p=0.20$ and 0.005$)$.

Calculated $\mathrm{CaO}_{2}-\mathrm{C} \bar{\nu} \mathrm{O}_{2}$ values are reported in Fig. 2. No differences were found among all four conditions whether at rest or at exercise steady state. As expected, $\mathrm{CaO}_{2}-\mathrm{C} \bar{\nu} \mathrm{O}_{2}$ was higher at exercise than at rest in all conditions $(p<0.05)$.

\section{Kinetics responses}

Individual examples of the time course of $\mathrm{HR}$ and $\mathrm{CO}$ kinetics upon exercise onset are shown in Fig. 3.

In no case $d_{1}$ differed from 0 , so we retained no time delay for $\varphi_{1}$. Parameters of the double exponential equation describing HR kinetics are shown in Fig. 4. In control, $\varphi_{1}$ was visible in the whole cohort in upright and supine

position, except for one subject in the latter body position. Under atropine, $\varphi_{1}$ was identified only in five subjects in supine and in two subjects in upright position. The magnitude of $A_{1}$ was smaller in atropine than in control $(p<0.001$ and 0.05). Similar results were found when $A_{1}$ was expressed as a percentage of $\Delta \mathrm{HR}$ (in the supine position, $A_{1}$ was $50 \pm 21 \%$ in control and $11 \pm 14 \%$ in atropine, $p<0.05$; in the upright position, $A_{1}$ was $70 \pm 16 \%$ in control and $11 \pm 22 \%$ in atropine, $p<0.05) . A_{2}$ was smaller in upright position both in control $(p<0.05)$ and under vagal blockade $(p<0.001)$. Concerning $\tau_{1}$, the lack of values under atropine, especially in an upright posture $(n=2)$ makes a statistical comparison meaningless. In supine posture, $\tau_{2}$ was larger in atropine than in control $(p<0.05)$.

The parameters of the double exponential equation describing the $\mathrm{CO}$ kinetics at the exercise onset are shown in Fig. 5. For CO, $A_{1}$ was lower in atropine than in control 


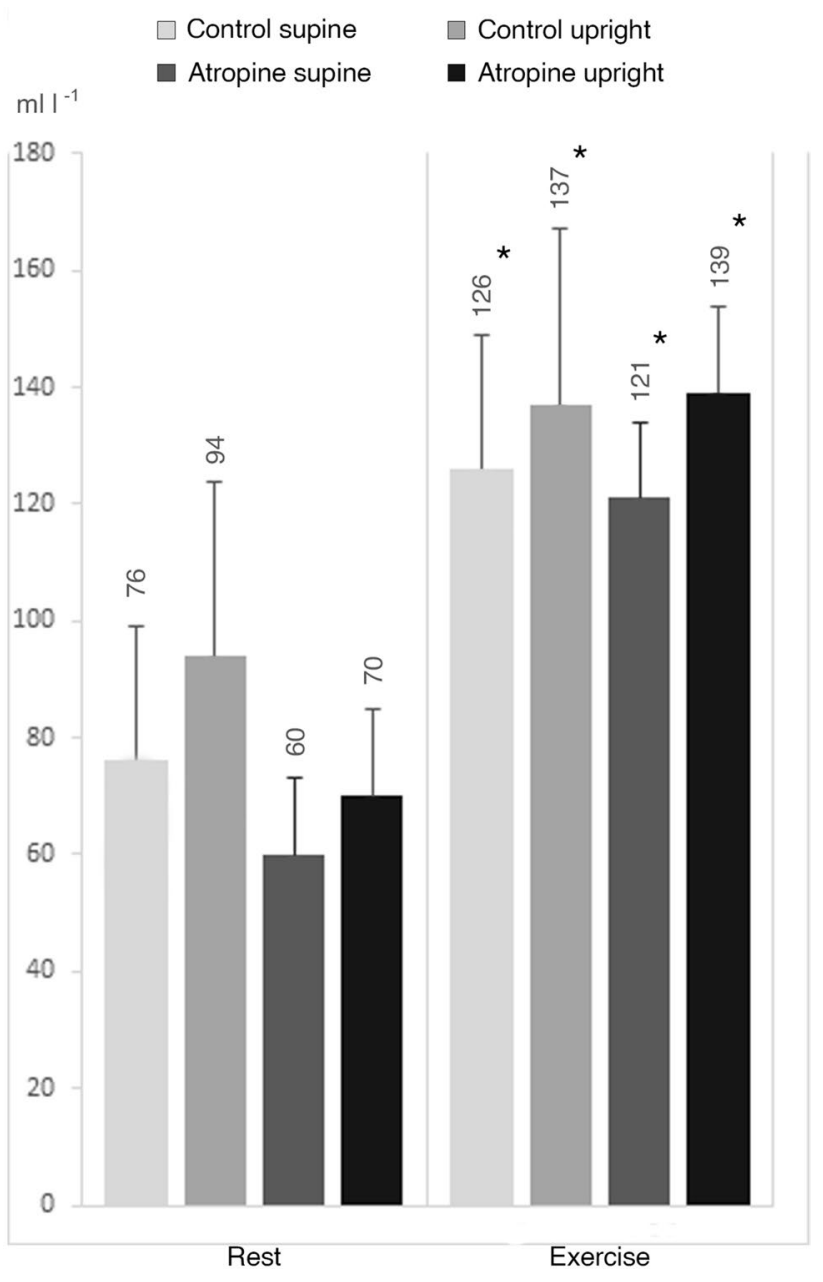

Fig. 2 Calculated arterial-venous $\mathrm{O}_{2}$ difference between rest and exercise steady state in supine and upright position and for control situation and with atropine. $\mathrm{CaO}_{2}-\mathrm{Cv} \mathrm{O}_{2}$ arterial-venous $\mathrm{O}_{2}$ difference; $* p<0.05$ vs. rest

in the upright position $(p<0.05)$. No significant difference in $\tau_{1}$ was found, neither for body position ( $p=0.98$ and 0.51$)$ nor for atropine ( $p=0.57$ and 0.09$)$. The values of $A_{2}$ were the same in all conditions ( $p=0.97$ and 0.38$)$. In atropine, $\tau_{2}$ was lower in the upright than supine position $(p<0.001)$. In supine posture, $\tau_{2}$ was higher in atropine than in control $(p<0.05)$. Notwithstanding, we also remark that the $\tau_{2}$ mean value in atropine was affected by an outlier value ( $\tau_{2}$ of 101.4 , at the limit of two SD above the group mean).

Double exponential analysis was applied to $\dot{V} \mathrm{O}_{2}$ kinetics in all subjects, in all experimental conditions. Parameters of the double exponential equation describing $\dot{V} \mathrm{O}_{2}$ kinetics at the exercise onset are shown in Fig. 6. In atropine, $A_{2}$ and $\tau_{2}$ were lower in the upright than in supine position $(p<0.05)$.

\section{Discussion}

This study provides the first demonstration of the effects of parasympathetic blockade on the cardiorespiratory response during exercise transients. Under atropine, $\varphi_{1}$ for HR was almost completely suppressed suggesting that the $A_{1}$ for $\mathrm{CO}$ response kinetics was determined uniquely by the changes in SV. The lower values of $A_{1}$ for $\mathrm{CO}$ found during exercise performed after atropine injection, compared to the control condition, corresponds to the contribution of HR to the $\varphi_{1}$ in CO kinetics. These findings are in agreement with what we originally hypothesized and they represent the most current quantitative demonstration of the role of the inhibition of vagal modulation of HR at exercise start in determining the early $\mathrm{CO}$ response. The pattern followed by the different pertinent variables are analysed herewith, as an introduction to a holistic discussion of $\varphi_{1}$ kinetics.

\section{Heart rate}

The observation that under vagal blockade in both postures the $A_{1}$ for HR was largely reduced, if not altogether suppressed, was not surprising. Fagraeus and Linnarsson (1976) were the first to analyse the rapid response of HR at exercise onset on a beat-by-beat basis. Although they did not model the transient kinetics, they observed that atropine remarkably slowed the overall HR response at exercise onset. Craig and Cummings (1963) reported what they called a "blocking effect" of atropine on the initial rapid HR increase, in a study in which HR was averaged over $10 \mathrm{~s}$ periods, thereby obtaining a dampened response. Later, using the supine knee extension model, Toska et al. (1994) confirmed that the initial rapid increase of HR at exercise onset was altered under atropine injection, thus demonstrating that the effect was independent of posture. Their results are in line with the present ones, as long as we found no differences concerning $A_{1}$ for HR between the two investigated postures. Lador et al. (2006) were the first who applied a double exponential model to the analysis of the HR kinetics, by extending the application range of the model developed by Barstow and Mole (1987) for the study of $\dot{V} \mathrm{O}_{2}$ kinetics. Based on the results of Fagraeus and Linnarsson (1976), Lador et al. (2006) postulated that the $A_{1}$ for HR was the result of withdrawal of vagal tone at exercise start. The same group provided two further indirect pieces of evidence supporting that conclusion. First, they found that the $A_{1}$ for HR was smaller in acute hypoxia than in normoxia (Lador et al. 2008) since in hypoxia, resting modulation of HR by the vagal system is blunted with respect to normoxia (Xie et al. 2001), resting HR is higher 

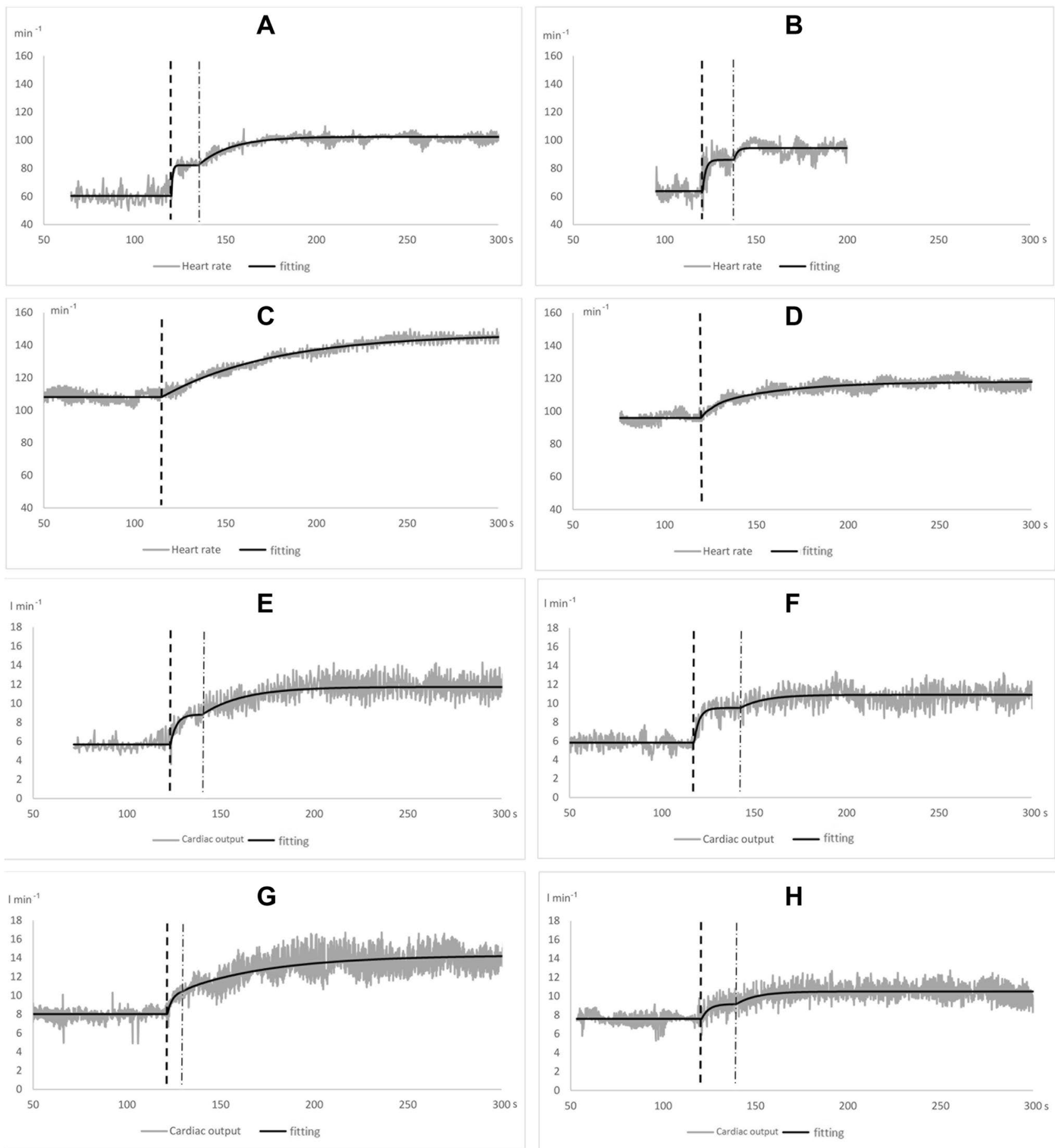

Fig. 3 Individual examples of the time course of heart rate and cardiac output in supine and upright position and for control situation and with atropine. Single beat data (grey trace) and corresponding fitting function (black line) are reported. A-D heart rate $\left(\mathrm{min}^{-1}\right) ; \mathbf{E}-\mathbf{H}$ : cardiac output $\left(\mathrm{L} \mathrm{min}^{-1}\right)$. Conditions: $\mathbf{A}, \mathbf{E}$ control supine; $\mathbf{B}, \mathbf{F}$ control upright; $\mathbf{C}, \mathbf{G}$ atropine supine; $\mathbf{D}, \mathbf{H}$ atropine upright. All traces

were fitted by the double exponential model (sum of two exponentials). However, fitting of the traces reported in $\mathbf{C}$ (atropine supine, heart rate) and D (atropine upright, heart rate) yielded phase I amplitude equal to zero: thus, they were fitted as monoexponential functions, due to the absence of phase I, as detailed in the method section 
$\square$ Control supine

Atropine supine

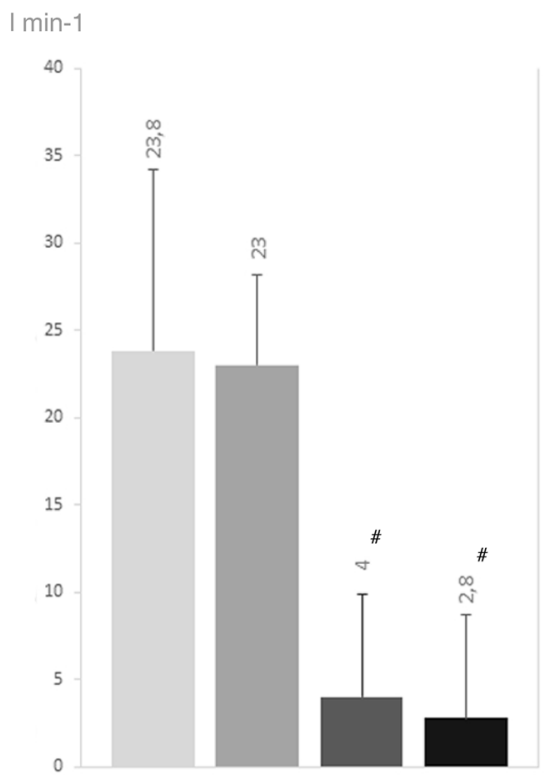

$\mathrm{A}_{1}$

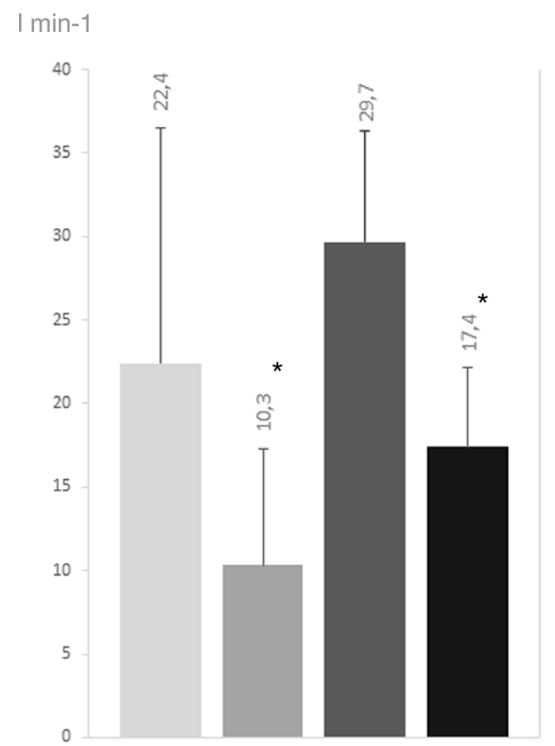

$\mathrm{A}_{2}$

Fig. 4 Heart rate kinetics between rest and exercise steady state in supine and upright position and for control situation and with atropine. $H R$ heart rate, $A$ amplitude, $\tau$ time constant. The subscripts $\square$ Control upright

- Atropine upright

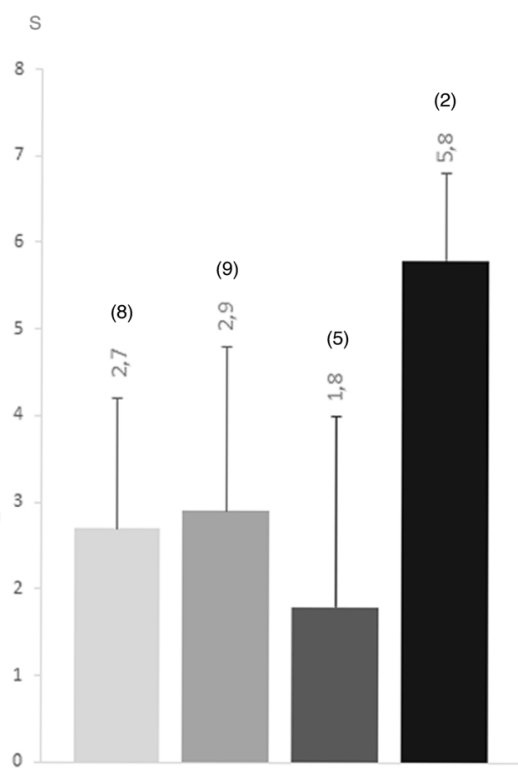

$\mathrm{T}_{1}$

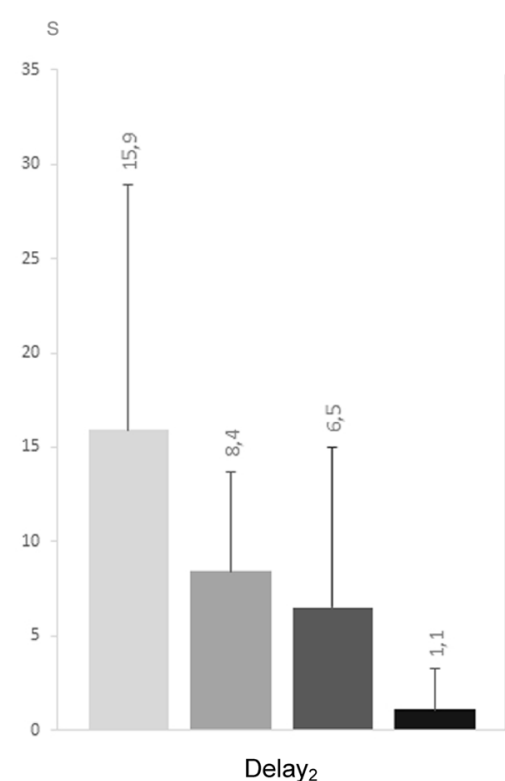

$\mathrm{T}_{2}$

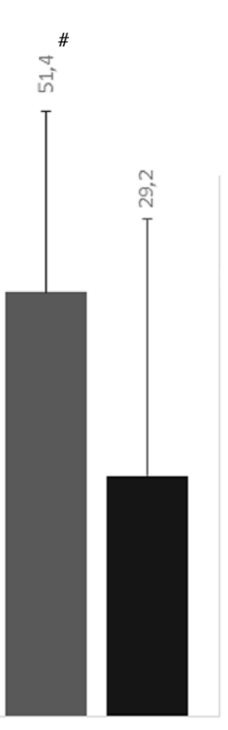

1 and 2 refer to the $\varphi_{1}$ and the $\varphi_{2}$ of the bi-exponential model; $(n)$ : number of subjects on which $\tau_{1}$ was computed; $* p<0.05$ vs. supine position; ${ }^{\#} p<0.05$ vs. control and $A_{1}$ for HR is lower in the former than in the latter case. Second, if vagal withdrawal occurs, its occurrence is immediate at the exercise start (Bringard et al. 2017).

As expected (Nyberg 1981; Toska and Eriksen 1993; Wray et al. 2001), the resting HR of our study was higher in atropine than in control (Table 1), whereas the $A_{1}$ was lower (Fig. 3). Therefore, the vagal modulation of the heart was already suppressed at rest, and no vagal withdrawal was possible at exercise onset. In control, the sum of resting HR (Table 1), and the $A_{1}$ of HR provides the theoretical $\varphi_{1}$ asymptote for HR. In control, this sum resulted 85 and $94 \mathrm{~min}^{-1}$ supine and upright, respectively. This means that in $\varphi_{1}$ the HR has increased by $24 \mathrm{~min}^{-1}$ supine and by $23 \mathrm{~min}^{-1}$ upright above the respective resting values. Under atropine, 


\section{$\square$ Control supine $\quad \square$ Control upright \\ Atropine supine $\quad$ Atropine upright}
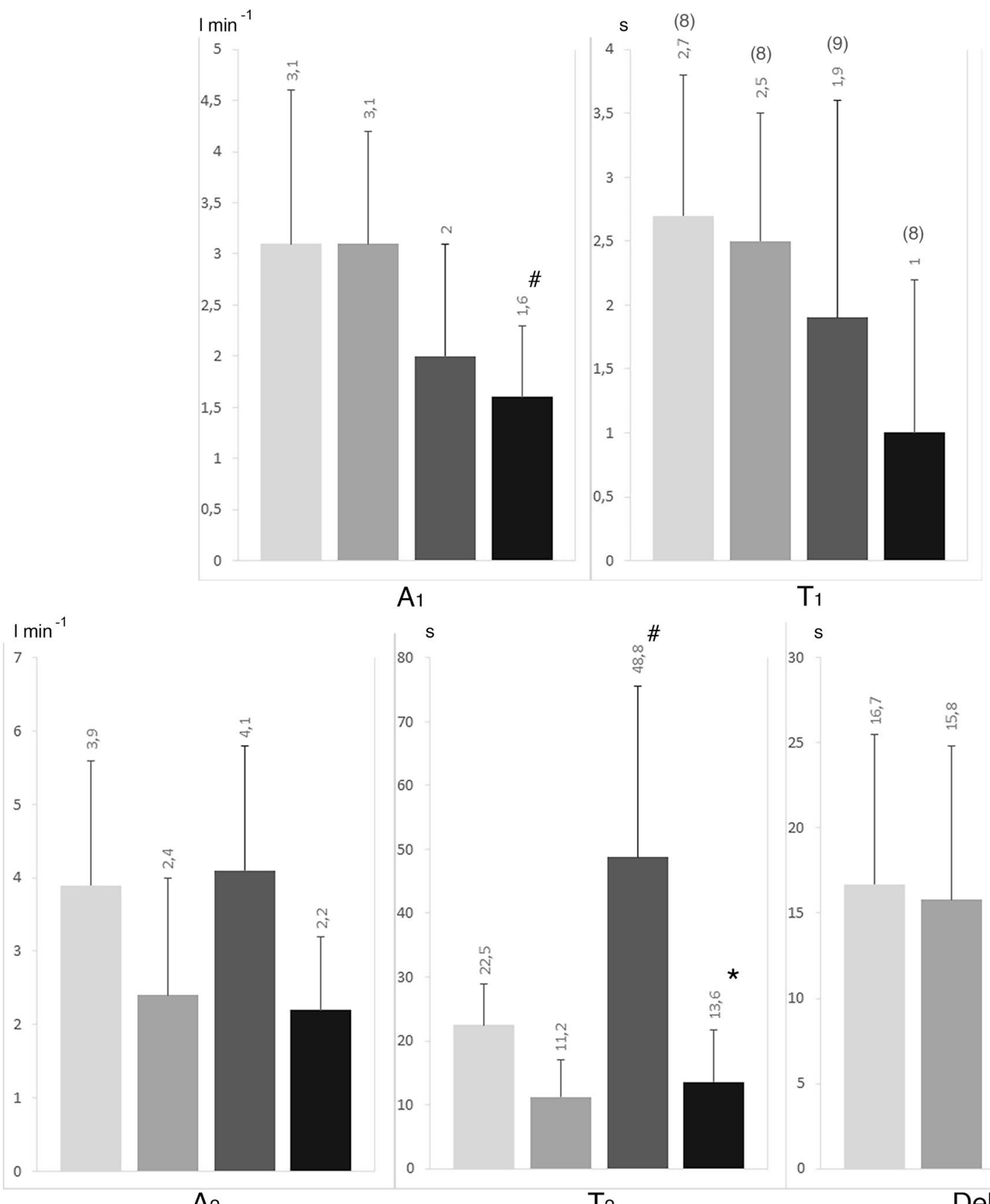

\section{$A_{1}$}

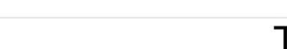

\section{$\mathrm{T}_{1}$}
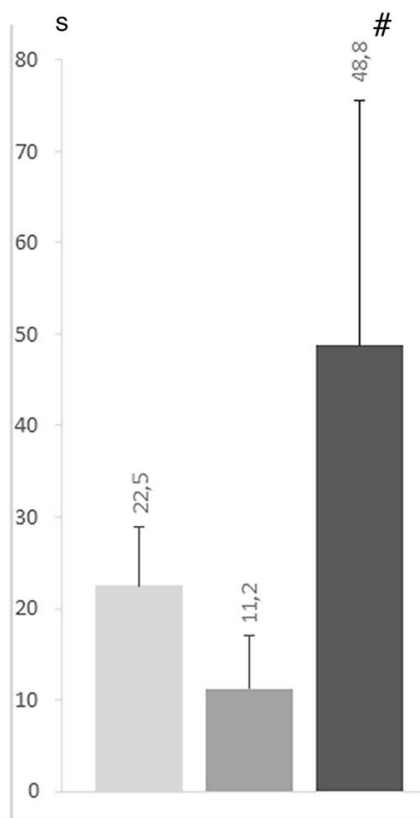

$\mathrm{T}_{2}$
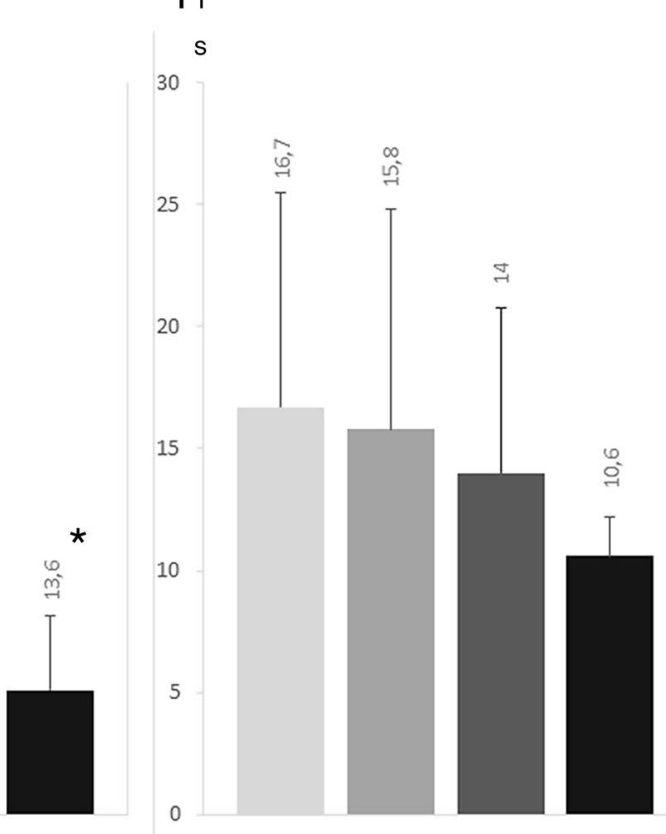

Delay $_{2}$

Fig. 5 Cardiac output kinetics between rest and exercise steady state in supine and upright position and for control situation and with atropine. $C O$ cardiac output, $A$ amplitude, $\tau$ time constant. The subscripts

the $\varphi_{1}$ asymptote for HR was 109 and $111 \mathrm{~min}^{-1}$, supine and upright, respectively. The former value is identical to the resting HR supine, the latter was only $5 \mathrm{~min}^{-1}$ higher than the resting HR value upright.
1 and 2 refer to the $\varphi_{1}$ and the $\varphi_{2}$ of the bi-exponential model; $(n)$ : number of subjects on which $\tau_{1}$ was computed. $* p<0.05$ vs. supine position; ${ }^{\#} p<0.05$ vs. control

In heart transplant recipients, the basal HR at rest is in the range 100-112 $\mathrm{min}^{-1}$ (Pflugfelder et al. 1987; Convertino et al. 1990; Shephard 1992; Backman et al. 1997; Grassi et al. 1997; Strobel et al. 1999; Ferretti et al. 2002; 


\section{Control supine}

Atropine supine
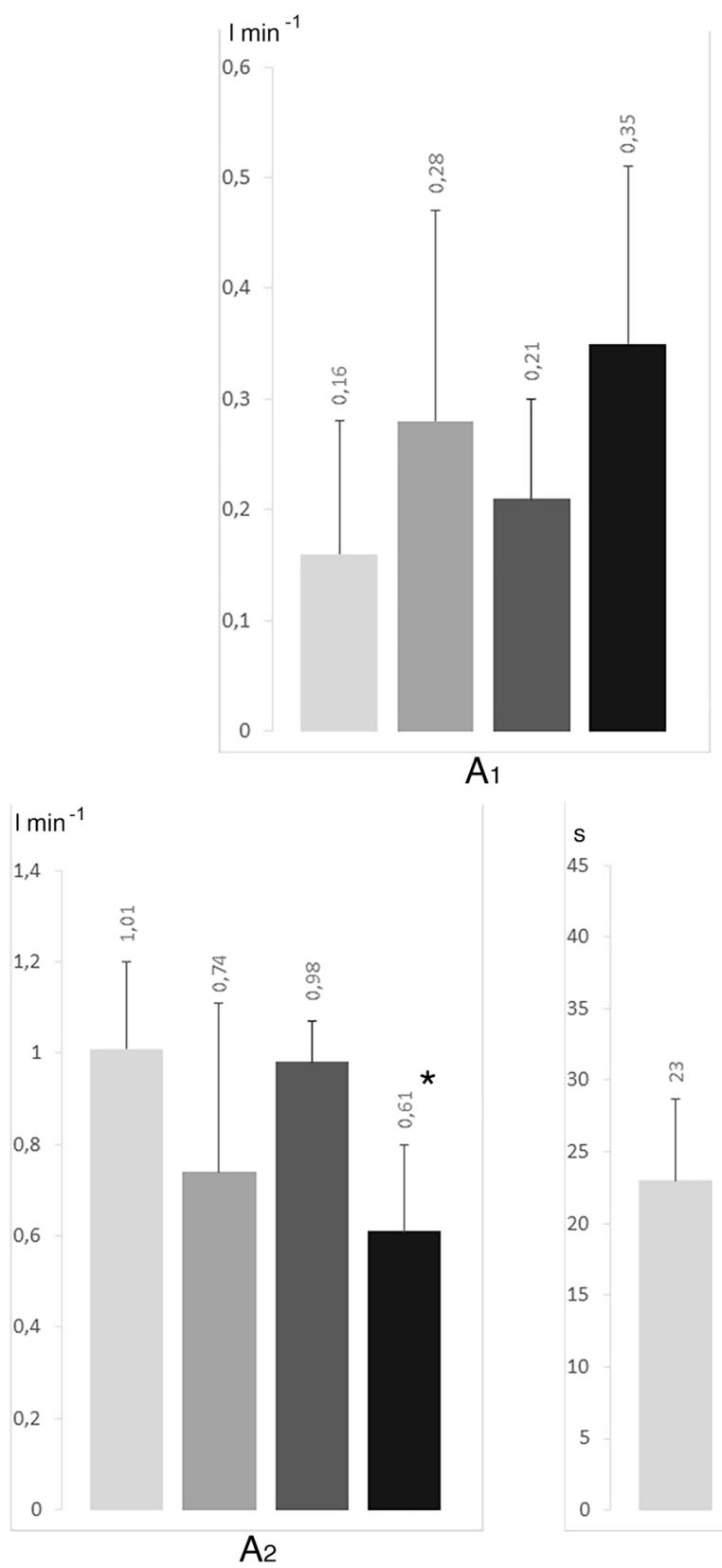

\section{Control upright}

atropine upright

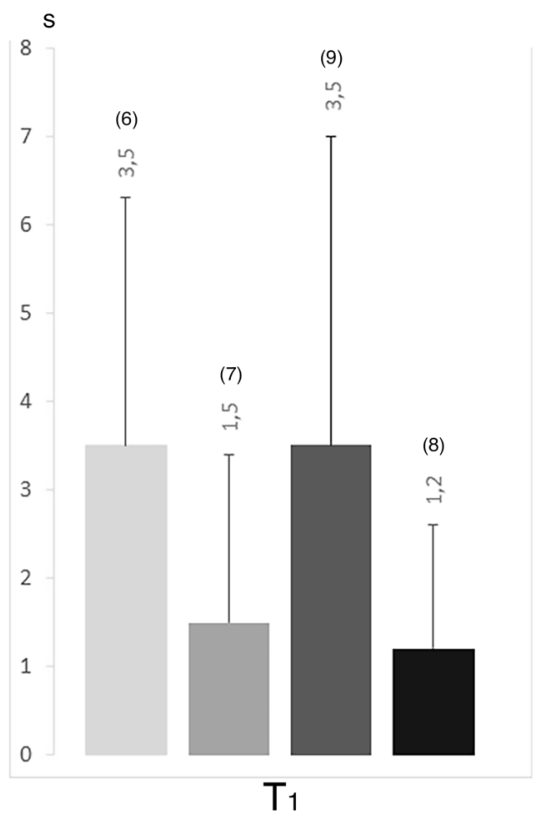

$\mathrm{T}_{1}$
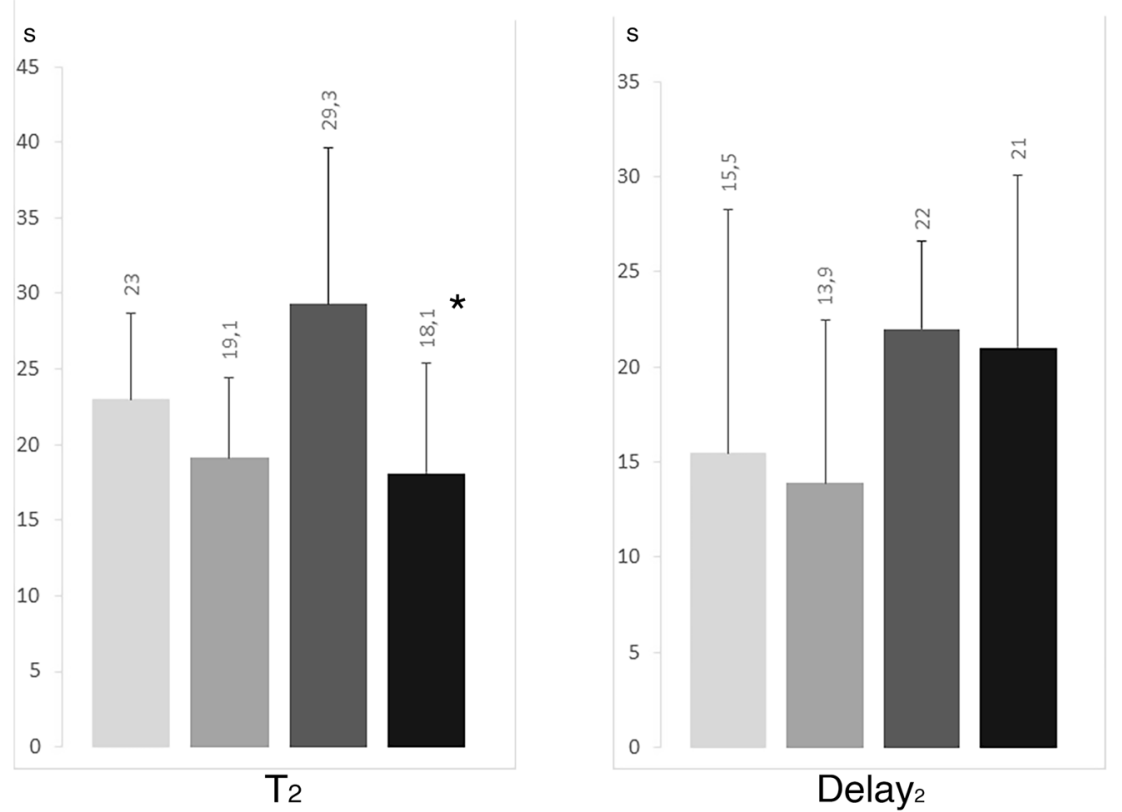

Fig.6 Oxygen consumption kinetics at rest and exercise steady state in supine and upright position and for control situation and with atropine. $\dot{V} \mathrm{O}_{2}$ oxygen uptake, $A$ amplitude, $\tau$ : time constant. The sub-

scripts 1 and 2 refer to the $\varphi_{1}$ and the $\varphi_{2}$ of the bi-exponential model; (n): number of subjects on which $\tau_{1}$ was computed. $* p<0.05$ vs. supine position

Kaufmann et al. 2007). In atropine, independently of the posture, the resting HR values are fully within this range, indicating complete suppression of cardiac vagal control by atropine. Coherently, the $\varphi_{1}$ asymptote for HR under atropine remained practically equal to the resting HR. This is due to the extremely low $A_{1}$ amplitude in atropine, as a result of a lack of vagal withdrawal at exercise start (the

vagus is already inhibited at rest). Our hypothesis was that vagal withdrawal explains the HR increase in $\varphi_{1}$ at exercise onset, and these findings confirmed our original assumption. Nevertheless, the $\varphi_{1}$ asymptote for HR was higher under atropine than in control. If our hypothesis was correct, these data would suggest that in control, at the power used for this study, the withdrawal of vagal tone upon exercise start was 
incomplete, as the HR at the asymptote of $\varphi_{1}$ remains lower than that we would expect under parasympathetic blockade. The equal magnitude of $A_{1}$ in supine and upright indicates that the HR response in $\varphi_{1}$ is independent of body posture.

In $\varphi_{2}$, the time constant was similar to that of previous studies (Lador et al. 2006, 2013). $A_{2}$ is smaller in the upright than supine in control, a condition in which both branches of the autonomic nervous system are active. Under atropine, the resting HR is the same, yet the $A_{2}$ is smaller upright than supine. This may mean that resting HR is mostly determined by the parasympathetic heart modulation, whereas the degree of sympathetic system stimulation during exercise determines the amplitude of the $\varphi_{2}$ HR response. This interpretation would be compatible with the hypothesis proposed by Lador et al. (2006) of a predominant sympathetic role in $A_{2}$ for HR.

The sum of $A_{1}$ plus $A_{2}$ is the overall HR response to exercise and it should correspond to $\Delta \mathrm{HR}$. A comparison between these two parameters shows that this is the case indeed. In fact, the sum of $A_{1}$ plus $A_{2}$, expressed in $\mathrm{min}^{-1}$, was $46 \pm 5$ in control supine, $34 \pm 7$ in control upright, $33 \pm 4$ in atropine supine, $20 \pm 6$ in atropine upright. A comparison of these values with the $\Delta \mathrm{HR}$ data reported in Fig. 1 shows that the former corresponds well to the latter in each condition.

\section{Cardiac output}

Different patterns appear concerning CO responses. Contrary to HR, CO shows a positive $\varphi_{1}$ response under atropine and control experimental conditions. However, $A_{1}$ is smaller in atropine than in control, because in atropine the $\varphi_{1}$ response is entirely due to SV response, considering the $A_{1}$ for HR negligible. In this condition, it is possible to distinguish the SV role from the HR role in determining the $\varphi_{1} \mathrm{CO}$ response. Both in supine and in upright posture, the $\mathrm{CO}$ response due to $\mathrm{SV}$ in control is equal to the $A_{1}$ for $\mathrm{CO}$ in atropine; the fraction of the $\mathrm{CO}$ response due to $\mathrm{HR}$ in control is equal to the difference between the $A_{1}$ for $\mathrm{CO}$ in control and the $A_{1}$ for $\mathrm{CO}$ in atropine. Is this difference compatible with the $\varphi_{1}$ increase for HR? This is hard to establish because $\mathrm{SV}$ is also a matter of telediastolic volume, which depends on the diastole duration, which is shorter in atropine than in control. Nevertheless, it is a matter of fact that these results show that atropine reduced $A_{1}$ for $\mathrm{CO}$ but did not suppress it. It was reduced because of the suppression of $A_{1}$ for HR. Thus, the remaining yet lower $\mathrm{CO}$ response in $\varphi_{1}$ under atropine cannot be a consequence of vagal withdrawal, because there is no vagal withdrawal between rest and exercise in this case: the parasympathetic system is inhibited all time long. It cannot be due to increased sympathetic stimulation at exercise, because the $\varphi_{1}$ duration is too short for that. If sympathetic stimulation plays a role, it would be responsible only for the $\varphi_{2} \mathrm{CO}$ response, both for its chronotropic and inotropic effect on the heart.

These results confirm the hypothesis of the muscle pump mechanism, originally proposed by Sheriff et al. (1993) on animals and later resumed to explain the $\mathrm{CO}$ increase in heart transplant recipients (Meyer et al. 1998). This mechanism, which was finally demonstrated also in healthy humans under Lower Body Negative Pressure (Fagoni et al. 2020), may well operate to determine the entire $\varphi_{1} \mathrm{CO}$ response when the vagal system is blocked and therefore there is no HR contribution to the $\varphi_{1}$ CO kinetics.

\section{Oxygen uptake}

Concerning the $\dot{V} \mathrm{O}_{2}$ kinetics, $\varphi_{1}$ was visible in all conditions. There was no decrease of following atropine injection. Lador et al. (2006) showed, with the Fick principle, that the $\varphi_{1}$ amplitude of the CO kinetics explains entirely the $\varphi_{1}$ amplitude of the $\dot{V} \mathrm{O}_{2}$ kinetics, in line with the cardiodynamic hypothesis of Wasserman et al. (1974). Because of a delay between muscle $\mathrm{O}_{2}$ consumption and lung $\mathrm{O}_{2}$ uptake (DeLorey et al. 2003), we can assume that the composition of $A_{1}$ mixed venous blood remains unchanged during the first seconds of exercise, and thus arterial-venous $\mathrm{O}_{2}$ difference $\left(\mathrm{CaO}_{2}-\mathrm{C} \bar{v} \mathrm{O}_{2}\right)$ stays equal to that at rest. In fact this assumption is not in clear contrast with the kinetics of $\mathrm{CaO}_{2}-\mathrm{C} \overline{\mathrm{v}} \mathrm{O}_{2}$ that we could estimate after Casaburi et al (1989), who determined a kinetics of mixed venous oxygen saturation $\left(\mathrm{S}_{\bar{v}} \mathrm{O}_{2}\right)$ with a time resolution of $4 \mathrm{~s}$ and characterised by a half-time of $32 \mathrm{~s}$ (time constant of approximately $46 \mathrm{~s}$ ): within the time resolution of $\varphi_{1}$ this would imply a negligible error indeed. Thus, if we assume that $\mathrm{CaO}_{2}-\mathrm{C} \bar{\nu} \mathrm{O}_{2}$ stays equal to that at rest, and we accept the cardiodynamic hypothesis of Wasserman et al (1974), we can thus predict the change in $A_{1}$ for $\dot{V} \mathrm{O}_{2}$ by applying the Fick principle and multiplying $A_{1}$ for $\mathrm{CO}$ and $\mathrm{CaO}_{2}-\mathrm{C} \bar{\nu} \mathrm{O}_{2}$ at rest (Lador et al. 2006). The predicted $A_{1}$ for $\dot{V} \mathrm{O}_{2}$ is compared with the one that we determined in this study using the double exponential model in Table 3.

Table 3 Measured and recalculated $\dot{V} \mathrm{O}_{2}$ kinetics increase at rest and during exercise steady state, in control condition and with atropine

\begin{tabular}{|c|c|c|c|c|c|}
\hline$\Delta \dot{V} \mathrm{O}_{2}$ & & $\begin{array}{l}\text { Control } \\
\text { supine } \\
N=6\end{array}$ & $\begin{array}{l}\text { Control } \\
\text { upright } \\
N=7\end{array}$ & $\begin{array}{l}\text { Atropine } \\
\text { supine } \\
N=9\end{array}$ & $\begin{array}{l}\text { Atropine } \\
\text { upright } \\
N=8\end{array}$ \\
\hline Measured & $\mathrm{L} \min ^{-1}$ & 0.23 & 0.37 & 0.21 & 0.39 \\
\hline $\begin{array}{l}\text { Recalcu- } \\
\text { lated }\end{array}$ & $\mathrm{L} \min ^{-1}$ & 0.24 & 0.33 & $0.11^{*}$ & $0.11^{*}$ \\
\hline
\end{tabular}

Measured and recalculated $\dot{V} \mathrm{O}_{2}$ kinetics increase at rest and during exercise steady state, in control condition and with atropine

$\dot{V} \mathrm{O}_{2}$ oxygen uptake

$* p<0.01$ vs. measured 
The correspondence between recalculated and measured $A_{1}$ values for $\dot{V} \mathrm{O}_{2}$ is excellent in control, as was the case in Lador et al (2006). Conversely, in atropine, the calculated $A_{1}$ was much less than the observed $A_{1}$ for $\dot{V} \mathrm{O}_{2}(p<0.01$ both supine and upright). Several hypotheses have been formulated to explain the CO-induced $\dot{V} \mathrm{O}_{2}$ increase (De Cort et al. 1991; Yoshida et al. 1993; Leyk et al. 1995; Lador et al. 2006). We highlight an intriguing speculative hypothesis, among these. In a previous study published by our group, the combined analysis of the HR and the mean arterial pressure (MAP) responses, at the onset of exercise, has shown that the $\varphi_{1}$ HR increase, which we attribute to vagal withdrawal, corrects the immediate fall of MAP due to sudden muscle vasodilatation (Bringard et al. 2017). In that study, the increase in HR occurs along a baroreflex sequence, the sensitivity of which is equal to that observed not only at exercise steady state (Iellamo et al. 1994, 1997; Vallais et al. 2009), but also after vagal blockade (Fontolliet et al. 2018). Vagal withdrawal is immediate, then HR follows with some inertia (positive $\tau_{1}$ ) along a baroreflex curve whose operational point is displaced from the centring point. We speculate that this baroreflex response may play a role in the coupling of the $\mathrm{CO}$ and the $\dot{V} \mathrm{O}_{2}$ response. If this is correct, then in atropine there would not be the HR increase, but baroreceptor stimulation would persist, thus maintaining an intact ventilatory response, which is not under vagal blockade, contrary to the heart. An analysis of the dynamics of baroreflex responses in the early phase of exercise should help in better focusing and analysing this issue: this should be the object of a further study.

If the baroreflexes are involved in coupling the $\mathrm{CO}$ and the $\dot{V} \mathrm{O}_{2}$ response, the mechanism that determines $\dot{V} \mathrm{O}_{2} A_{1}$ : (1) is neural; (2) is generated outside the lungs and is likely to operate at the brain stem level (several hypotheses exist on this subject, see e.g. Lador et al. (2013); (3) has effects on the heart that are mediated by the vagal system; (4) generate an integrated response such that a stronger stimulus is sent to the lungs than to the heart; (5) is calibrated in such a way as to provide $\dot{V} \mathrm{O}_{2}$ responses that are compatible, in terms of gas exchange, with the $\mathrm{CO}$ responses.

It goes without saying that the $\varphi_{1} \dot{V} \mathrm{O}_{2}$ kinetics, especially if it has a "cardiodynamic" origin, is unrelated to events occurring within the muscles. In fact, the double exponential model, dissociates, at least as far as $\varphi_{1}$ is concerned, from the muscle oxygen consumption kinetics, the control of which is metabolic (Ferretti 2015).

\section{Steady-state phase}

Ekblom et al. (1972) and Fagraeus and Linnarsson (1976) reported that HR was higher at rest, but lower at exercise steady state in atropine compared to control. This result was confirmed later by Toska et al. (1994) and Fisher et al.
(2013), the latter using glycopyrrolate to induce parasympathetic blockade. Our results are in line with those of Kelbaek et al. (1991), who reported higher HR and CO, at rest in both upright and supine posture, with atropine than in control. Using a slightly lower intensity of exercise than ours, Kelbaek et al. (1991) reported higher HR and CO at exercise steady-state in an upright posture with atropine, contrary to the present study, where the higher HR was associated with unchanged $\mathrm{CO}$ under atropine compared to control. This discrepancy could arise from the difference in exercise intensity used between these studies or from the semi-recumbent posture used by those authors. Ekblom et al. (1972) reported no alteration of CO neither at rest (contrary to the present study) nor during submaximal exercise, (in agreement with our study), under atropine, compared to control. Of note, the amount of atropine was lower in Ekblom et al (1972) study (2.0-2.5 mg), compared to the current one.

Contrary to our findings, Ekblom et al. (1972) and Davies et al. (1976) did not observe the modification of steady-state $\dot{V} \mathrm{O}_{2}$ during moderate exercise in upright posture, under atropine. Using normobaric hypoxia, which has been postulated to reduce vagal activity and increase sympathetic activity at rest, Lador et al (2008) observed that rest and exercise steady-state values for $\mathrm{HR}$ and $\mathrm{CO}$ were increased, without any change for $\dot{V} \mathrm{O}_{2}$.

\section{Conclusions}

In conclusion, atropine administration suppresses $\varphi_{1}$ for HR almost completely, in agreement with the vagal withdrawal concept at exercise onset. Therefore, only SV changes determine $A_{1}$ for $\mathrm{CO}$ response after atropine injection. The differences in $A_{1}$ for $\mathrm{CO}$ between atropine and control highlight the contribution of HR to the $A_{1}$ for CO. These results provide the first direct demonstration of the effects of inhibition of vagal modulation of $\mathrm{HR}$ at exercise onset on the $\varphi_{1} \mathrm{CO}$ kinetics.

Author contributions $\mathrm{TF}, \mathrm{AB}$ and GF conceived and/or designed the work. AB, AA and ET conducted experiments. TF, AB, AA, NF, ET and $\mathrm{AT}$ participated in the acquisition, analysis and interpretation of data. TF, AB, and GF wrote the manuscript. All authors read and approved the manuscript.

Funding Open Access funding provided by Université de Genève. This study was supported by Swiss National Science Foundation Grants 32003B_127620 and 3200B0-114033 to Guido Ferretti.

Data availability The data that support the findings of this study are available from the corresponding author upon reasonable request. 
Code availability Not applicable.

\section{Declarations}

Conflict of interest No conflicts of interest, financial or otherwise, are declared by the authors.

Ethical approval The study was approved by the ethical committee of the Geneva University Hospital (approval CER: 06-184 NAC 06-058) and was conducted in accordance with the Declaration of Helsinki for use of human subjects.

Consent to participate Subjects were fully informed of the nature and possible risks of the experimental procedures before their written informed consent was obtained. They were aware of the right of withdrawing from the study at any time without jeopardy.

Consent for publication All authors approved the final version of the manuscript, agree to be accountable for all aspects of the work in ensuring that questions related to the accuracy or integrity of any part of the work are appropriately investigated and resolved. All persons designated as authors qualify for authorship, and all those who qualify for authorship are listed.

Open Access This article is licensed under a Creative Commons Attribution 4.0 International License, which permits use, sharing, adaptation, distribution and reproduction in any medium or format, as long as you give appropriate credit to the original author(s) and the source, provide a link to the Creative Commons licence, and indicate if changes were made. The images or other third party material in this article are included in the article's Creative Commons licence, unless indicated otherwise in a credit line to the material. If material is not included in the article's Creative Commons licence and your intended use is not permitted by statutory regulation or exceeds the permitted use, you will need to obtain permission directly from the copyright holder. To view a copy of this licence, visit http://creativecommons.org/licenses/by/4.0/.

\section{References}

Adami A, Fagoni N, Ferretti G (2014) The Q - - ` O2 diagram: an analytical interpretation of oxygen transport in arterial blood during exercise in humans. Respir Physiol Neurobiol 193:55-61

Backman SB, Gilron I, Robbins R (1997) Protamine-induced hypotension and bradycardia in a cardiac transplant patient. Can J Anaesth 44:520-524

Barker RC, Hopkins SR, Kellogg N, Olfert IM, Brutsaert TD, Gavin TP, Entin PL, Rice AJ, Wagner PD (1999) Measurement of cardiac output during exercise by open-circuit acetylene uptake. J Appl Physiol 87:1506-1512

Barstow TJ, Molé PA (1987) Simulation of pulmonary O2 uptake during exercise transients in humans. J Appl Physiol 63:2253-2261

Bringard A, Adami A, Moia C, Ferretti G (2014) A new interpolationfree procedure for breath-by-breath analysis of oxygen uptake in exercise transients. Eur J Appl Physiol 114:1983-1994

Bringard A, Adami A, Fagoni N, Fontolliet T, Lador F, Moia C, Tam E, Ferretti G (2017) Dynamics of the RR-interval versus blood pressure relationship at exercise onset in humans. Eur J Appl Physiol 117:619-630. https://doi.org/10.1007/s00421-017-3564-6

Capelli C, Cautero M, di Prampero PE (2001) New perspectives in breath-by-breath determination of alveolar gas exchange in humans. Pflügers Arch 441:566-577. https://doi.org/10.1007/ s004240000429
Capelli C, Cautero M, Pogliaghi S (2011) Algorithms, modelling and $\mathrm{VO}_{2}$ kinetics. Eur J Appl Physiol 111:331-342. https://doi.org/10. 1007/s00421-010-1396-8

Carson E, Cobelli C, Finkelstein L (1983) The mathematical modelling of metabolic and endocrine systems. John Wiley \& Sons, New York

Casaburi R, Daly J, Hansen JE, Effros RM (1989) Abrupt changes in mixed venous blood gas composition after the onset of exercise. J Appl Physiol 67:1106-1112

Convertino VA, Thompson CA, Benjamin BA, Keil LC, Savin WM, Gordon EP, Haskell WL, Schroeder JS, Sandler H (1990) Haemodynamic and $\mathrm{ADH}$ responses to central blood volume shifts in cardiac-denervated humans. Clin Physiol 10:55-67

Craig FN, Cummings EG (1963) Slowing of the heart at the beginning of exercise. J Appl Physiol 18:353-356. https://doi.org/10. 1152/jappl.1963.18.2.353

Cummin AR, Iyawe VI, Mehta N, Saunders KB (1986) Ventilation and cardiac output during the onset of exercise, and during voluntary hyperventilation, in humans. J Physiol 370:567-583. https://doi.org/10.1113/jphysiol.1986.sp015951

Davies CT, Brotherhood JR, Few JD, Zeidifard E (1976) Effects of beta blockade and atropinisation on plasma catecholamine concentration during exercise. Eur J Appl Physiol Occup Physiol $36: 49-56$

De Cort SC, Innes JA, Barstow TJ, Guz A (1991) Cardiac output, oxygen consumption and arteriovenous oxygen difference following a sudden rise in exercise level in humans. J Physiol 441:501-512. https://doi.org/10.1113/jphysiol.1991.sp018764

DeLorey DS, Kowalchuk JM, Paterson DH (2003) Relationship between pulmonary $\mathrm{O}_{2}$ uptake kinetics and muscle deoxygenation during moderate-intensity exercise. J Appl Physiol 95:113-120. https://doi.org/10.1152/japplphysiol.00956.2002

di Prampero PE (1981) Energetics of muscular exercise. Rev Physiol Biochem Pharmacol 89:143-222

Ekblom B, Goldbarg AN, Kilbom A, Astrand PO (1972) Effects of atropine and propranolol on the oxygen transport system during exercise in man. Scand J Clin Lab Invest 30:35-42

Eriksen M, Waaler BA, Walløe L, Wesche J (1990) Dynamics and dimensions of cardiac output changes in humans at the onset and at the end of moderate rhythmic exercise. J Physiol 426:423-437. https://doi.org/10.1113/jphysiol.1990.sp018147

Fagoni N, Bruseghini P, Adami A, Capelli C, Lador F, Moia C, Tam E, Bringard A, Ferretti G (2020) Effect of lower body negative pressure on phase I cardiovascular responses at exercise onset. Int J Sports Med 41(4):209-218. https://doi.org/10.1055/a-1028-7496 (Epub 2020 Jan 20)

Fagraeus L, Linnarsson D (1976) Autonomic origin of heart rate fluctuations at the onset of muscular exercise. J Appl Physiol 40:679682. https://doi.org/10.1152/jappl.1976.40.5.679

Faisal A, Beavers KR, Robertson AD, Hughson RL (2009) Prior moderate and heavy exercise accelerate oxygen uptake and cardiac output kinetics in endurance athletes. J Appl Physiol 106:1553-1563. https://doi.org/10.1152/japplphysiol.91550.2008

Ferretti G (2015) Energetics of muscular exercise. Springer International Publishing, Cham. https://doi.org/10.1007/ 978-3-319-05636-4

Ferretti G, Marconi C, Achilli G, Caspani E, Fiocchi R, Mamprin F, Gamba A, Ferrazzi P, Cerretelli P (2002) The heart rate response to exercise and circulating catecholamines in heart transplant recipients. Pflugers Arch 443:370-376

Ferretti G, Licker MJ, Anchisi S, Moia C, Susta D, Morel DR (2005) The effects of 1-adrenergic blockade on cardiovascular oxygen flow in normoxic and hypoxic humans at exercise. Eur J Appl Physiol 95:250-259. https://doi.org/10.1007/s00421-005-1393-5

Ferretti G, Fagoni N, Taboni A, Bruseghini P, Vinetti G (2017) The physiology of submaximal exercise: the steady state concept. 
Respir Physiol Neurobiol 246:76-85. https://doi.org/10.1016/j. resp.2017.08.005

Fisher JP, Adlan AM, Shantsila A, Secher JF, Sørensen H, Secher NH (2013) Muscle metaboreflex and autonomic regulation of heart rate in humans. J Physiol 591:3777-3788

Fontolliet T, Pichot V, Bringard A, Fagoni N, Adami A, Tam E, Furlan R, Barthélémy JC, Ferretti G (2018) Testing the vagal withdrawal hypothesis during light exercise under autonomic blockade: a heart rate variability study. J Appl Physiol 125:1804-1811. https:// doi.org/10.1152/japplphysiol.00619.2018

Goldberger JJ, Challapalli S, Tung R, Parker MA, Kadish AH (2001) Relationship of heart rate variability to parasympathetic effect. Circulation 10:1977-1983. https://doi.org/10.1161/01.CIR.103. 15.1977

Grassi B, Marconi C, Meyer M, Rieu M, Cerretelli P (1997) Gas exchange and cardiovascular kinetics with different exercise protocols in heart transplant recipients. J Appl Physiol 82:1952-1962. https://doi.org/10.1152/jappl.1997.82.6.1952

Grønlund J (1984) A new method for breath-to-breath determination of oxygen flux across the alveolar membrane. Eur J Appl Physiol Occup Physiol 52:167-172. https://doi.org/10.1007/BF00433387

Iellamo F, Hughson RL, Castrucci F, Legramante JM, Raimondi G, Peruzzi G et al (1994) Evaluation of spontaneous baroreflex modulation of sinus node during isometric exercise in healthy humans. Am J Physiol 267:994-1001

Iellamo F, Legramante JM, Raimondi G, Peruzzi G (1997) Baroreflex control of sinus node during dynamic exercise in humans: effects of central command and muscle reflexes. Am J Physiol 272(3 Pt 2):H1157-1164

Kaufmann PA, Rimoldi OE, Gnecchi-Ruscone T, Luscher TF, Camici PG (2007) Systemic nitric oxide synthase inhibition improves coronary flow reserve to adenosine in patients with significant stenoses. Am J Physiol Heart Circ Physiol 293:H2178-2182

Kelbaek H, Marving J, Hvid-Jacobsen K, Nielsen SL (1991) Effects of atropine on left ventricular volumes and ejection and filling rates at rest and during exercise. Br J Clin Pharmacol 32:585-589

Kenfack MA, Lador F, Licker M, Moia C, Tam E, Capelli C, Morel D, Ferretti G (2004) Cardiac output by Modelflow method from intra-arterial and fingertip pulse pressure profiles. Clin Sci (lond) 106:365-369

Lador F, Kenfack MA, Moia C, Cautero M, Morel DR, Capelli C, Ferretti G (2006) Simultaneous determination of the kinetics of cardiac output, systemic $\mathrm{O}_{2}$ delivery, and lung $\mathrm{O}_{2}$ uptake at exercise onset in men. Am J Physiol Integr Comp Physiol 290:R1071R1079. https://doi.org/10.1152/ajpregu.00366.2005

Lador F, Tam E, Kenfack MA, Cautero M, Moia C, Morel DR, Capelli C, Ferretti G (2008) Phase I dynamics of cardiac output, systemic $\mathrm{O}_{2}$ delivery, and lung $\mathrm{O}_{2}$ uptake at exercise onset in men in acute normobaric hypoxia. Am J Physiol Integr Comp Physiol 295:R624-R632. https://doi.org/10.1152/ajpregu.00797.2007

Lador F, Tam E, Adami A, Kenfack MA, Bringard A, Cautero M, Moia C, Morel DR, Capelli C, Ferretti G (2013) Cardiac output, $\mathrm{O}_{2}$ delivery and $\mathrm{VO}_{2}$ kinetics during step exercise in acute normobaric hypoxia. Respir Physiol Neurobiol 186:206-213

Laughlin MH (1987) Skeletal muscle blood flow capacity: role of muscle pump in exercise hyperemia. Am J Physiol 253:H993-1004. https://doi.org/10.1152/ajpheart.1987.253.5.H993

Leyk D, Essfeld D, Hoffmann U, Wunderlich HG, Baum K, Stegemann J (1994) Postural effect on cardiac output, oxygen uptake and lactate during cycle exercise of varying intensity. Eur J Appl Physiol Occup Physiol 68:30-35

Leyk D, Hoffmann U, Baum K, Essfeld D (1995) Time courses of cardiac output and oxygen uptake following stepwise increases in exercise intensity. Int J Sports Med 16:357-363

Linnarsson D, Sundberg CJ, Tedner B, Haruna Y, Karemaker JM, Antonutto G, di Prampero PE (1996) Blood pressure and heart rate responses to sudden changes of gravity during exercise. Am J Physiol 270:H2132-H2142. https://doi.org/10.1152/ajpheart. 1996.270.6.H2132

Meyer M, Scheid P (1980) Solubility of acetylene in human blood determined by mass spectrometry. J Appl Physiol 48:1035-1037. https://doi.org/10.1152/jappl.1980.48.6.1035

Meyers BF, Patterson GA (1998) Technical aspects of adult lung transplantation. Semin Thorac Cardiovasc Surg 10:213-20.

Morikami Y, Yasue H, Okumura K, Horio Y, Fujii H, Matsuyama $\mathrm{K}$ (1988) Effects of phentolamine and atropine on angina pectoris induced by handgrip test in patients with variant angina. Am J Cardiol 61:71-76. https://doi.org/10.1016/0002-9149(88) 91307-0

Nyberg G (1981) Vagal and sympathetic contributions to the heart rate at rest and during isometric and dynamic exercise in young healthy men. J Cardiovasc Pharmacol 3:1243-1250

Pflugfelder PW, Purves PD, McKenzie FN, Kostuk WJ (1987) Cardiac dynamics during supine exercise in cyclosporine-treated orthotopic heart transplant recipients: assessment by radionuclide angiography. J Am Coll Cardiol 10:336-341

Poole DC, Jones AM (2012) Oxygen uptake kinetics. Compr Physiol 2:933-996. https://doi.org/10.1002/cphy.c100072

Schneider SM, Watenpaugh DE, Lee SMC, Ertl AC, Williams WJ, Ballard RE, Hargens AR (2002) Lower-body negative-pressure exercise and bed-rest-mediated orthostatic intolerance. Med Sci Sports Exerc 34:1446-1453. https://doi.org/10.1249/01.MSS. 0000027761.31366 .06

Shephard RJ (1992) Responses of the cardiac transplant patient to exercise and training. Exerc Sport Sci Rev 20:297-320

Sheriff DD, Rowell LB, Scher AM (1993) Is rapid rise in vascular conductance at onset of dynamic exercise due to muscle pump? Am J Physiol 265:H1227-1234

Stenger MB, Evans JM, Knapp CF, Lee SMC, Phillips TR, Perez SA, Moore AD, Paloski WH, Platts SH (2012) Artificial gravity training reduces bed rest-induced cardiovascular deconditioning. Eur J Appl Physiol 112:605-616. https://doi.org/10.1007/ s00421-011-2005-1

Strobel JS, Epstein AE, Bourge RC, Kirklin JK, Kay GN (1999) Nonpharmacologic validation of the intrinsic heart rate in cardiac transplant recipients. J Interv Card Electrophysiol 3:15-18

Sundblad P, Haruna Y, Tedner B, Linnarsson D (2000) Short-term cardiovascular responses to rapid whole-body tilting during exercise. Eur J Appl Physiol 81:259-270. https://doi.org/10.1007/s0042 10050041

Tam E, Kenfack MA, Cautero M, Lador F, Antonutto G, di Prampero PE, Ferretti G, Capelli C (2004) Correction of cardiac output obtained by Modelflow from finger pulse pressure profiles with a respiratory method in humans. Clin Sci (lond) 106:371-376. https://doi.org/10.1042/CS20030302

Toska K, Eriksen M (1993) Respiration-synchronous fluctuations in stroke volume, heart rate and arterial pressure in humans. J Physiol 472:501-512

Toska K, Eriksen M, Walløe L (1994) Short-term cardiovascular responses to a step decrease in peripheral conductance in humans. Am J Physiol 266(1 Pt 2):H199-211. https://doi.org/10.1152/ajphe art.1994.266.1.H199

Vallais F, Baselli G, Lucini D, Pagani M, Porta A (2009) Spontaneous baroreflex sensitivity estimates during graded bicycle exercise: a comparative study. Physiol Meas 30:201-213

van Lieshout JJ, Toska K, van Lieshout EJ, Eriksen M, Walløe L, Wesseling KH (2003) Beat-to-beat noninvasive stroke volume from arterial pressure and Doppler ultrasound. Eur J Appl Physiol 90:131-137. https://doi.org/10.1007/s00421-003-0901-8

Wasserman K, Whipp BJ, Castagna J (1974) Cardiodynamic hyperpnea: hyperpnea secondary to cardiac output increase. J Appl Physiol 36:457-464. https://doi.org/10.1152/jappl.1974.36.4.457 
Wesseling KH, Jansen JR, Settels JJ, Schreuder JJ (1993) Computation of aortic flow from pressure in humans using a nonlinear, threeelement model. J Appl Physiol 74:2566-2573. https://doi.org/10. 1152/jappl.1993.74.5.2566

Whipp BJ, Ward SA (1990) Physiological determinants of pulmonary gas exchange kinetics during exercise. Med Sci Sports Exerc 22:62-71

Whipp BJ, Ward SA, Lamarra N, Davis JA, Wasserman K (1982) Parameters of ventilatory and gas exchange dynamics during exercise. J Appl Physiol 52:1506-1513. https://doi.org/10.1152/ jappl.1982.52.6.1506

White DW, Raven PB (2014) Autonomic neural control of heart rate during dynamic exercise: revisited. J Physiol 592:2491-2500. https://doi.org/10.1113/jphysiol.2014.271858

Wieling W, Harms MPM, ten Harkel ADJ, van Lieshout JJ, Sprangers RLH (1996) Circulatory response evoked by a $3 \mathrm{~s}$ bout of dynamic leg exercise in humans. J Physiol 494:601-611. https://doi.org/10. 1113/jphysiol.1996.sp021518

Wray DW, Formes KJ, Weiss MS, O-Yurvati AH, Raven PB, Zhang R, Shi X (2001) Vagal cardiac function and arterial blood pressure stability. Am J Physiol Heart Circ Physiol 281:H1870-1880
Xie A, Skatrud JB, Dempsey JA (2001) Effect of hypoxia on the hypopnoeic and apnoeic threshold for $\mathrm{CO}(2)$ in sleeping humans. J Physiol 535:269-278. https://doi.org/10.1111/j.1469-7793.2001. 00269.x

Yasue H, Horio Y, Nakamura N, Fujii H, Imoto N, Sonoda R, Kugiyama K, Obata K, Morikami Y, Kimura T (1986) Induction of coronary artery spasm by acetylcholine in patients with variant angina: possible role of the parasympathetic nervous system in the pathogenesis of coronary artery spasm. Circulation 74:955-963. https://doi.org/10.1161/01.CIR.74.5.955

Yoshida T, Yamamoto K, Udo M (1993) Relationship between cardiac output and oxygen uptake at the onset of exercise. Eur J Appl Physiol Occup Physiol 66:155-160. https://doi.org/10.1007/ BF01427057

Publisher's Note Springer Nature remains neutral with regard to jurisdictional claims in published maps and institutional affiliations. 